\title{
Sternal closure: Wires are still the king!
}

\author{
Sertaç Çiçek, MD
}

From the Department of Surgery, Mayo Clinic College of Medicine and Science, Rochester, Minn; and Department of Cardiovascular Surgery, Mayo Clinic, Rochester Minn.

Disclosures: Author has nothing to disclose with regard to commercial support.

Received for publication April 24, 2018; accepted for publication April 25, 2018; available ahead of print Aug 10, 2018.

Address for reprints: Sertaç Çiçek, MD, Department of Cardiovascular Surgery, Mayo Clinic College of Medicine and Science, Mayo Clinic, 200 First St, Rochester, MN 55905 (E-mail: Cicek.m@mayo.edu).

J Thorac Cardiovasc Surg 2018;156:1596-7

$0022-5223 / \$ 36.00$

Copyright (c) 2018 by The American Association for Thoracic Surgery

https://doi.org/10.1016/j.jtcvs.2018.04.106

Although median sternotomy was first described by Milton in 1897, it was a rarely used procedure until its reintroduction by Julian in $1957 .{ }^{1}$ It has since then revolutionized the field of cardiothoracic surgery, providing easy, fast, and unobstructed access to the heart and great vessels. It is well known from orthopedics practice that mechanical conditions at the fracture site are determined by fixation stability and reapproximation. Mechanical conditions during the early phase of bone healing are important determinants for the healing outcome. ${ }^{2}$ Median sternotomy not only has become one of the most common osteotomies performed but also has made cardiothoracic surgery the only specialty to adopt a simple wire approximation technique for the vast majority of patients in a complicated area with unique challenges for healing because of respiratory and upper body movements. Sternal closure with wires has become the standard because of the ease of use, the speed of use, the relatively low complication rate, and the low cost of wires. Common closure methods use a series of wires, either interrupted or figure-of-eight to secure the sternal halves created during the median sternotomy. All wiring techniques, however, allow some movement and separation of sternal halves under physiologic loads. These minimal movements do not cause any problems in the vast majority of patients with healthy sternums unless the sternotomy is technically faulty, and they may even promote faster bone healing by stimulating early callus formation.

Sternal wound complications are reported to occur in $0.5 \%$ to $6.1 \%$ of patients after cardiac surgery, and they pose a serious risk to affected patients. In particular, deep sternal wound complications are associated with a mortality between $14 \%$ and $47 \% .^{3}$ Because of the high morbidity, mortality, and associated cost, sternal complications are now considered never-events by Medicare. Several innovative closure techniques, including reinforced wires, primary plating, and cables, have been proposed for maximizing sternal stability, especially in high-risk patients; however, a reliable technique has been difficult to find.

In their study in this issue of the Journal, Marasco and associates ${ }^{4}$ randomly allocated 120 patients to undergo either

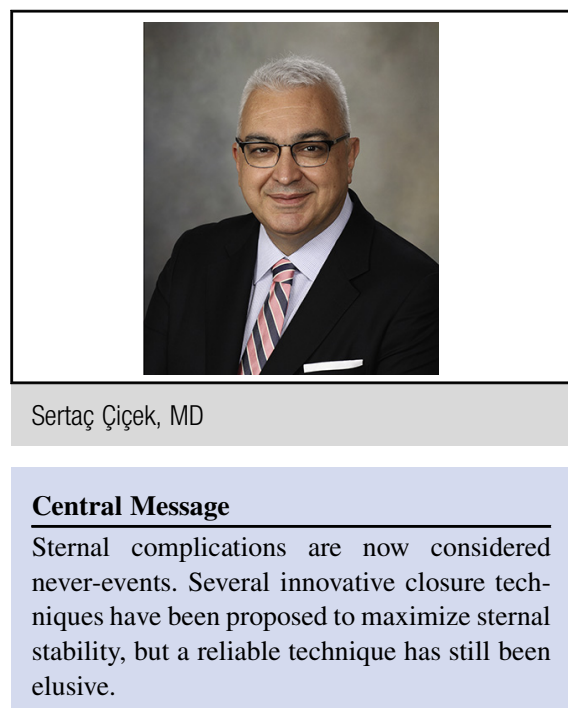

See Article page 1589 .

standard wire closure $(n=60)$ or closure with the ZIPFIX (DePuy Synthes, West Chester, Pa) sternal closure system $(\mathrm{n}=58)$. The primary outcomes were pain and analgesia requirements in the early postoperative period. The major secondary outcomes were sternal wound infection and sternal movement on ultrasound at the postoperative follow-up visit. Marasco and associates ${ }^{4}$ hypothesized that biocompatible plastic cable ties would achieve a more rigid sternal fixation, thus reducing postoperative pain and analgesia requirements. Three patients in the ZIPFIX group had early reopening for bleeding; interestingly, they underwent reclosure with wires! In all 3 patients who had deep sternal infection develop, standard wires were also used for final closure. No demonstrable benefit was shown in the primary outcome for patients in the ZIPFIX group, and that group had significantly more movement in the sternum and manubrium on ultrasound at 4 postoperative weeks. The cost of closure was almost 20 times higher with the ZIPFIX system than with wire closure. Any ideal sternal closure should ensure stability, a reduced rate of postoperative complications, and a short hospitalization period, along with costeffectiveness. The ZIPFIX technique has not provided better outcomes than conventional steel wires. This may be due to the selection of low-risk patients, for whom the expected sternal complication rate would be low and in whom any benefit would be difficult to be shown.

Further evaluation of these alternatives in the form of a randomized, controlled trial is required to demonstrate benefit both in reduced sternal complications and in 
improvement in quality of life. especially in the high-risk patient groups. Rigorous cost analyses are necessary to assess the cost-effectiveness of these adjuncts. Until then, sternal wiring will continue to be the king!

\section{References}

1. Gerbode F, Braimbridge MV, Melrose DG. Median sternotomy for open cardiac surgery during total heart-lung by-pass. AMA Arch Surg. 1958;76:821-4.
2. Klein P, Schell H, Streitparth F, Heller M, Kassi JP, Kandziora F, et al. The initial phase of fracture healing is specifically sensitive to mechanical conditions. $\mathrm{J} \mathrm{Or}$ thop Res. 2003;21:662-9.

3. Balachandran S, Lee A, Denehy L, Lin KY, Royse A, Royse C, et al. Risk factor for sternal complications after cardiac operations: a systematic review. Ann Thorac Surg. 2016;102:2109-17.

4. Marasco SF, Fuller L, Zimmet A, McGiffin D, Seitz M, Ch'ng S, et al. Prospective, randomized, controlled trial of polymer cable ties versus standard wire closure of midline sternotomy. J Thorac Cardiovasc Surg. 2018;156:1589-95. 